Ruey-Hong Wong · Jung-Der Wang Ling-Ling Hsieh · Tsun-Jen Cheng

\title{
XRCC1, CYP2E1 and ALDH2 genetic polymorphisms and sister chromatid exchange frequency alterations amongst vinyl chloride monomer-exposed polyvinyl chloride workers
}

Received: 27 September 2002 / Accepted: 26 March 2003 / Published online: 9 May 2003

(C) Springer-Verlag 2003

\begin{abstract}
Vinyl chloride monomer (VCM) is a known human carcinogen, which may be metabolized by cytochrome P450 2E1 (CYP2E1), aldehyde dehydrogenase 2 (ALDH2), and glutathione $S$-transferase T1 (GSTT1). A DNA-repair gene, X-ray repair cross-complementing group 1 ( $X R C C 1$, exon 10), may also be implicated in the process of VCM-related carcinogenesis. Thus, VCM-exposed workers with inherited susceptible metabolic and DNA-repair genotypes may experience an increased risk of genotoxiciy. This study was designed to investigate whether metabolic and DNA-repair genotypes affected sister chromatid exchange (SCE) frequency in occupationally VCM-exposed workers from polyvinyl chloride (PVC) manufacturing plants. Study subjects comprised 61 male workers having experienced VCM exposure, and 29 male controls. Questionnaires were administered to obtain detailed histories of cigarette-smoking habits, alcohol consumption behavior, and occupation. The frequency of SCE in peripheral lymphocytes was determined using a standardized method, and genotypes of CYP2E1, $A L D H 2, G S T T 1$ and XRCC1 were identified by the polymerase chain reaction (PCR) procedure. Our results demonstrated that smoking, age and VCM exposure and $X R C C 1 \quad(P=0.03), C Y P 2 E 1 \quad(P=0.04)$, and $A L D H 2$
\end{abstract}

R.-H. Wong $\cdot$ J.-D. Wang $\cdot$ T.-J. Cheng $(\bowtie)$

Institute of Occupational Medicine and Industrial Hygiene, College of Public Health, National Taiwan University,

No. 1 Ren-Ai Rd., Sec. 1, 10018 Taipei, Taiwan

E-mail: tcheng@ha.mc.ntu.edu.tw

Tel.: + 886-2-23957845

Fax: + 886-2-23957845

R.-H. Wong · J.-D. Wang · T.-J. Cheng

National Taiwan University Hospital, 10018, Taipei, Taiwan

L.-L. Hsieh

Department of Public Health, College of Medicine,

Chang Gung University, 33341 Tao-Yuan, Taiwan

Present address: R.-H. Wong

Department of Public Health, College of Health Care and

Management, Chung Shan Medical University, 40242 Taichung, Taiwan
$(P=0.08)$ were significantly associated with an increased SCE frequency. Further analysis of gene combinations, including $C Y P 2 E 1, A L D H 2$ and $X R C C 1$, revealed an increased trend for these genotypes to influence SCE frequencies for the low VCM-exposure group $(P<0.01)$, but not so for the high VCM-exposure group $(P=0.29)$ or for controls $(P=0.49)$. These results suggest that workers with susceptible metabolic and DNA-repair genotypes, may experience an increased risk of DNA damage elicited by VCM exposure.

Keywords Vinyl chloride monomer C $C Y P 2 E 1$. $A L D H 2 \cdot X R C C 1 \cdot$ Sister chromatid exchange

\section{Introduction}

Vinyl chloride monomer (VCM; CAS No. 75-01-4) has been associated with angiosarcoma of liver in previous epidemiological studies (Theriault and Allard 1981; Jones et al. 1988; Wong et al. 1991). Our previous retrospective cohort study revealed that Taiwanese polyvinyl chloride (PVC) factory workers have a greater standardized mortality ratio (SMR) of liver cancer than the general male population (Wong et al. 2002a). Importantly, only 25 of these VCM-exposed workers developed liver cancer between 1985 and 1997. Those individuals experiencing a greater risk of developing cancers may possess certain susceptibility factors including inherited metabolic and DNA-repair traits.

Subsequent to metabolic activation in the liver by cytochrome P450 2E1 (CYP2E1; el Ghissassi et al.1998), VCM is transformed into the alkylating intermediates chloroethylene oxide (CEO) and chloroacetaldehyde (CAA), both of which may bind covalently with DNA to form DNA adducts (Guengerich 1992). CEO may then be metabolized by glutathione $S$-transferases (GSTs; Whysner et al. 1996), and CAA by aldehyde dehydrogenase 2 (ALDH2; Whysner et al. 1996). Our previous study has also revealed that CYP2E1 and ALDH2 are 
associated with an increased frequency of SCE amongst VCM-exposed workers, although the small number of subjects in that study has precluded us from drawing any firm conclusion in this regard (Wong et al. 1998).

In addition to metabolic traits, DNA repair capacity also plays an important role in VCM-related carcinogenesis. Evidence has been presented to indicate that VCM derivative etheno-DNA adducts may be repaired though the base excision repair (BER) pathway (Dosanjh et al. 1994). X-ray cross-complementing group 1 (XRCC1), a DNA-repair protein involved in singlestrand breaks and the BER pathway, has been reported to be responsible for the efficient repair of DNA damage caused by ionization and alkylating agents (Thompson et al. 1990). Three polymorphisms of DNA-repair genes XRCC1 have been identified at codon 194 (Arg to Trp), 280 (Arg to His), and 399 (Arg to Gln) (Shen et al. 1998). In particular, XRCC1 399Gln polymorphism resulting in single base substitution, which may affect binding with PARP [poly (ADP-ribose) polymerase], may lead to deficiency of DNA repair (Marintchev et al. 2000). Our recent study showed that VCM-exposed workers with higher cumulative dose had an increased plasma mutant p53 protein and anti-p53 antibody. In the same study, workers with susceptible metabolic- and DNA-repair traits experienced higher levels of plasma mutant p53 protein and anti-p53 antibody (Wong et al. 2002b).

Previous studies have shown that workers exposed to VCM have a higher SCE frequency than controls (Sinues et al. 1991; Fucic et al. 1996). SCE frequency reflects recent VCM exposure in contrast to p53 gene mutation, which reflects cumulative VCM exposure. In this study, we used SCE as an indicator of DNA damage to investigate the effects of $X R C C 1, C Y P 2 E 1$, and $A L D H 2$ genotypes on DNA damage amongst VCMexposed workers.

\section{Materials and methods}

Study subjects and epidemiological data

Previously, we conducted a study to explore the association between SCE frequency and metabolic traits amongst 44 VCM-exposed workers at PVC manufacturing plants (Wong et al. 1998). In order to acquire sufficient statistical discriminatory power to detect differences in SCE frequency amongst various inherited polymorphisms in metabolic and DNA repair, we collected a greater number of study subjects than was the case for our previous study (Wong et al. 1998). In addition, we also included control subjects who had been exposed to neither VCM nor other mutagens at workplace.

A total of 61 male subjects from five PVC plants were recruited. Twenty-nine male controls were also selected from a resin-synthesis plant, where workers were exposed to dimethylformamide (DMF; CAS No. 68-12-2). Our previous study was unable to demonstrate any association between DMF exposure and SCE frequency alteration in peripheral lymphocytes from DMF-exposed workers (Cheng et al. 1999). Evidence from a comprehensive mutagenicity study, including an Ames test, indicates DMF is not a mutagen (Antoine et al. 1983).

In the current study, information was collected from study subjects by interviewer-administered questionnaires subsequent to informed consent having been provided by such subjects. The structured questionnaire contained questions that covered various demographic characteristics and life styles, including habits of cigarette-smoking and alcohol consumption, as well as a detailed occupational history. Each subject's smoking history included the number of cigarettes smoked daily and also the duration of the smoking habit. A parameter termed "pack-years" was coined as an indicator of cumulative smoking dose, and was defined as the number of packs of cigarettes smoked daily multiplied by the number of years of active smoking.

Our estimation of VCM exposure for this study's subjects was based upon our previously published work (Du et al. 1996) and also recently monitored air VCM levels (Cheng et al. 2001). A timeweighted average VCM-exposure level was assigned to each category of worker employment, those VCM-exposed workers in this study being categorized into one of two exposure groups, a high or a low VCM-exposure group. Individuals selected as belonging to the high VCM-exposure group had been exposed, occupationally, to a VCM concentration of greater than $1 \mathrm{ppm}$, whilst those from the low VCM-exposure group had been exposed to a VCM concentration of less than $1 \mathrm{ppm}$. An occupational exposure to VCM of $1 \mathrm{ppm}$ is the current permissible exposure limit in most developed countries (IPCS 1999).

\section{Sister chromatid exchange assay}

Sister chromatid exchange frequency assessment was performed according to a modified cytogenetic method (Wong et al. 1998). Briefly, $1 \mathrm{ml}$ whole blood was mixed with $9 \mathrm{ml}$ RPMI 1640 culture medium. Phytohemagglutinin was added at a concentration of $2 \mu \mathrm{g} / \mathrm{ml}$ to stimulate the division of lymphocytes. Cells were then incubated in $5 \% \mathrm{CO}_{2}$ in air at $37^{\circ} \mathrm{C}$ for $72 \mathrm{~h}$. At $24 \mathrm{~h}, 50 \mu \mathrm{M} 5$ bromodeoxyuridine was added to the culture in order to achieve differential staining. Colcemid $(0.1 \mu \mathrm{g} / \mathrm{ml})$ was added $1.5 \mathrm{~h}$ before harvesting. The lymphocytes were then harvested with hypotonic solution for $10 \mathrm{~min}$. Subsequently, cells were fixed in methanol:acetic acid $(3: 1, v / v)$. Slides were prepared and the chromosomes were stained by a modification of the fluorescence-plus Giemsa technique. For each subject, 50 cells at metaphase with 40 or more chromosomes present were scored to determine the individual mean SCE frequency per cell. All slides were scored by one reader who was blind to the determinants and exposure of each subject.

Genotyping of polymorphic metabolic and DNA-repair traits

The determination of $C Y P 2 E 1, A L D H 2$, and GSTT1 genotypes was performed as we have indicated previously (Wong et al. 1998). Briefly, for the CYP450 2E1 gene analysis, any restriction fragment length polymorphism (RFLP) was detected by differences in Pst $\mathbf{I}$ sites in the $5^{\prime}$-flanking region following PCR amplification, using methods described by Hayashi et al. (1991). Primers used for the amplification of $C Y P 2 E 1$ gene were $5^{\prime}$-CCA GTC GAG TCT ACA TTG TCA-3' and 5'-TTC ATT CTG TCT TCT AAC TGG-3'. Amplification was carried out under conditions such that the denaturing step was conducted at $95^{\circ} \mathrm{C}$, annealing at $55^{\circ} \mathrm{C}$ and extension at $72^{\circ} \mathrm{C}$. The PCR products were digested with PstI. Homozygous $c 1 c 1$ individuals exhibited a product fragment of $410 \mathrm{bp}$, whereas homozygous $c 2 c 2$ individuals revealed a $290 \mathrm{bp}$ and a $120 \mathrm{bp}$ fragment, and heterozygous $c 1 c 2$ individuals demonstrated all three fragments. The ALDH2-MboII polymorphism was determined by a modification of the methods as developed by Harada and Zhang (1993). The sequences of $A L D H 2$ primers were $5^{\prime}$-CAA ATT ACA GGG TCA ACT GCT ATG-3' and 5'-CCA CAC TCA CAG TTT TCT CTT-3'. Amplification was carried out under conditions such that the denaturing step was conducted at $94^{\circ} \mathrm{C}$, annealing at $52^{\circ} \mathrm{C}$ and extension at $65^{\circ} \mathrm{C}$. The PCR products were digested with $M b o \mathrm{II}$ and analyzed with $6 \%$ polyacrylamide gel electrophoresis 
(PAGE). Homozygous 2-2 individuals demonstrated a single product fragment of $135 \mathrm{bp}$, whereas homozygous $1-1$ individuals revealed both 125 and 10 bp fragments, and heterozygous $1-2$ individuals exhibited all three fragments. The GSTT1 genotype was determined as described by Pemble et al. (1994). Primers used for the GSTT1 gene were 5'-TTC CTT ACT GGT CCT CAC ATC TC-3' and 5'-TCA CCG GAT CAT GGC CAG CA-3'. The amplification of human $\beta$-globin (110 bp) was also performed as a positive control in each reaction to confirm the presence of amplifiable DNA in the samples. The primers used for $\beta$-globin were $5^{\prime}$-ACA CAA CTG TGT TCA CTA GC-3' and 5'-CAA CTT CAT CCA CGT TCA CC-3'. The amplification procedure was carried out under conditions such that denaturing was conducted at $94^{\circ} \mathrm{C}$, annealing at $52^{\circ} \mathrm{C}$, and extension at $65^{\circ} \mathrm{C}$. The reaction product then underwent electrophoresis in a $2 \%$ agarose gel. Individuals with GSTT1 alleles demonstrated a 480-bp fragment.

The XRCC1 exon-10-MspI polymorphism was determined using a PCR-RFLP technique (Duell et al. 2000). An Arg to Gln substitution in exon 10 (codon 399) was amplified to form an undigested fragment of $242 \mathrm{bp}$ using the primer pair $5^{\prime}$-CCC CAA GTA CAG CCA GGT C- $3^{\prime}$ and $5^{\prime}$-TGT CCC GCT CCT CTC AGT AG-3'. The amplification was carried out under conditions such that denaturing was conducted at $94^{\circ} \mathrm{C}$, annealing at $59^{\circ} \mathrm{C}$, and extension at $72^{\circ} \mathrm{C}$. The PCR products were digested with $M s p$ I and analyzed in a $2 \%$ agarose gel. Homozygous Gln-Gln individuals reflected a single product fragment of $242 \mathrm{bp}$, whereas homozygous Arg-Arg individuals demonstrated both 94 and $148 \mathrm{bp}$ fragments, and heterozygous $\mathrm{Arg}$-Gln individuals revealed all three fragments.

\section{Statistical analysis}

Comparisons between low and high VCM-exposure groups with the controls for age, duration of employment, current smoking status, pack-years of smoking, and alcohol consumption were made using Student's $t$-test and analysis of variance (ANOVA) for continuous variables, and using a $\chi^{2}$-test for discrete variables. The $\chi^{2}$-test was used to test the prevalence of genotypes of $X R C C 1, C Y P 2 E 1, A L D H 2$, and GSTT1 amongst low and high VCM-exposure groups and controls. Since workers possessing at least one XRCC1 Arg allele have previously been shown to possess a higher capacity for DNA repair than is the case for the $X R C C 1$ Gln allele (Shen et al. 1998), those with at least one $X R C C 1 \mathrm{Arg}$ allele were grouped as XRCC1 Arg-Arg/Arg-Gln genotypes. Similarly, individuals featuring the $C Y P 2 E 1$ genotype with at least one $c l$ allele demonstrate a lower enzyme activity level than is the case for those presenting a $C Y P 2 E 1 \quad c 2$ allele (Hayashi et al. 1991), and hence those with at least one CYP2E1 $c 1$ allele were grouped as $C Y P 2 E 1 \mathrm{clcl} / \mathrm{clc} 2$. Workers with at least one $A L D H 2^{2}$ allele also reflect a lower enzyme activity than $A L D H 2$ 1-1 (Crabb et al. 1989), and hence those with at least one $A L D H 2^{2}$ allele were grouped as $A L D H 2$ 1-2/2-2. Subsequently, the crude SCE frequency was evaluated using an analysis stratified by VCM exposure and different factors. ANOVA was used to compare difference in SCE frequencies by different VCM-exposure status, and a Student's $t$-test was used to test the association between age, duration of employment, smoking status, alcohol consumption, DNA repair, and different metabolic traits and associated SCE frequency. The association of these variables with SCE frequency was further assessed using a general linear model (GLM). Finally, a least-squares mean was performed to predict the adjusted SCE frequency for individuals with different numbers of susceptible XRCC1, CYP2E1, and $A L D H 2$ genotypes. In addition, GLM was also conducted to test for any trends in SCE frequency.

\section{Results}

Sixty-one male subjects with VCM exposure and 29 male controls were included in the analysis. The demographic characteristics of the study subjects are summarized in Table 1 . The mean age of the study subjects was 41.0 years, and $55.6 \%$ of the subjects were current smokers. The mean age $(P=0.29 ; t$-test $)$, duration of employment at PVC plants $(P=0.74)$, proportion of current smokers $\left(P=0.56 ; \chi^{2}\right.$-test $)$, the number of cigarette pack-years $(P=0.37)$ and alcohol consumption $(P=0.31)$ were not significantly different between the high and low VCMexposure groups. In contrast, however, controls were significantly younger in age, had a shorter duration of employment, and had smoked less pack-years of cigarettes.

The genotypic prevalence of XRCC1, CYP2E1, $A L D H 2$, and GSTT1 amongst the study subjects is shown in Table 2. The frequencies of the $399 \mathrm{Arg}$ and $399 \mathrm{Gln}$ alleles of $X R C C 1$ were $67.8 \%$ and $32.2 \%$, respectively, although a slightly higher prevalence of the $399 \mathrm{Gln}$ allele was observed for individuals who experienced a high VCM exposure $\left(P=0.06, \chi^{2}\right.$-test $)$. The frequencies of the $c 1$ and $c 2$ alleles of $C Y P 2 E 1$ were $77.8 \%$ and $22.2 \%$, respectively, and the frequencies of the $A L D H 2^{1}$ and $A L D H 2^{2}$ alleles were $68.3 \%$ and $31.7 \%$, respectively, whereas the prevalence of the GSTT1 null-type was $54.4 \%$ and that for the non-nulltype was $45.6 \%$.

The overall mean SCE frequency per cell was $8.2 \pm 0.2$. Table 3 summarizes the crude association of SCE frequency with various factors amongst test individuals. In this study, individuals experiencing a high VCM exposure revealed the highest SCE frequencies of 8.9 SCE/cell, followed by those classified as low VCM exposure (8.5 SCE/cell), and controls (7.2 SCE/cell; $P<0.01$, ANOVA). Similarly, workers older than 45 years of age or who were smokers also showed a
Table 1 Demographic characteristics of vinyl chloride monomer (VCM)-exposed polyvinyl chloride workers and controls stratified by different intensity of exposure. Data represent numbers of individuals, or means \pm SE for continuous variables

$* P=0.02, * * P<0.01$, ANOVA

\begin{tabular}{lllll}
\hline Variable & \multirow{2}{*}{ Controls } & \multicolumn{2}{l}{ VCM exposure } & \multirow{2}{*}{ All } \\
\cline { 3 - 4 } & & Low & High & \\
\hline Number of subjects & 29 & 29 & 32 & 90 \\
Age (years) & $34.0 \pm 1.0^{* *}$ & $45.7 \pm 1.6$ & $43.2 \pm 1.6$ & $41.0 \pm 1.0$ \\
Duration of employment (years) & $7.9 \pm 0.9^{* *}$ & $20.0 \pm 1.8$ & $19.2 \pm 1.7$ & $15.8 \pm 1.0$ \\
Smoking habit & $14(48.3 \%)$ & $16(55.2 \%)$ & $20(62.5 \%)$ & $50(55.6 \%)$ \\
$\quad \begin{array}{llll}\text { Number of current smokers (\%) } \\
\text { Pack-years }\end{array}$ & $4.4 \pm 1.0 *$ & $11.1 \pm 2.3$ & $8.7 \pm 1.6$ & $8.1 \pm 1.0$ \\
Alcohol consumption (g/week) & $20.8 \pm 15.1$ & $61.3 \pm 30.1$ & $27.0 \pm 13.9$ & $36.1 \pm 11.9$ \\
\hline
\end{tabular}


Table 2 Prevalence of genotypes of XRCC1, CYP2E1, ALDH2, and GSTT1 amongst vinyl chloride monomer (VCM)exposed workers and controls stratified by VCM exposure. Data represent the numbers of subjects (with percentage in parentheses, where shown)

\begin{tabular}{|c|c|c|c|c|c|}
\hline \multicolumn{2}{|l|}{ Genotype } & \multirow[t]{2}{*}{ Controls } & \multicolumn{2}{|c|}{ VCM exposure } & \multirow[b]{2}{*}{ All } \\
\hline Gene & Alleles & & Low & High & \\
\hline Number of subjects & & 29 & 29 & 32 & $90(100 \%)$ \\
\hline \multirow[t]{3}{*}{$X R C C 1$-exon 10} & $A r g-A r g$ & 15 & 15 & 9 & $39(43.3 \%)$ \\
\hline & $A r g-G \ln$ & 13 & 11 & 20 & $44(48.9 \%)$ \\
\hline & $G l n-G l n$ & 1 & 3 & $3^{*}$ & $7(7.8 \%)$ \\
\hline \multirow[t]{3}{*}{ CYP2E1 } & $c 1 c 1$ & 16 & 18 & 19 & $53(58.9 \%)$ \\
\hline & $c 1 c 2$ & 13 & 10 & 11 & $34(37.8 \%)$ \\
\hline & $c 2 c 2$ & 0 & 1 & 2 & $3(3.3 \%)$ \\
\hline \multirow[t]{3}{*}{$A L D H 2$} & $1-1$ & 13 & 15 & 15 & $43(47.8 \%)$ \\
\hline & $1-2$ & 14 & 10 & 13 & $37(41.1 \%)$ \\
\hline & $2-2$ & 2 & 4 & 4 & $10(11.1 \%)$ \\
\hline \multirow[t]{2}{*}{ GSTT1 } & Null & 17 & 13 & 19 & $49(54.4 \%)$ \\
\hline & Non-null & 12 & 16 & 13 & $41(45.6 \%)$ \\
\hline
\end{tabular}

Table 3 Frequencies of sister chromatid exchanges per cell stratified by VCM-exposure status and various factors

\begin{tabular}{|c|c|c|c|c|c|c|c|c|c|}
\hline \multicolumn{2}{|l|}{ Variables } & \multirow{2}{*}{\multicolumn{2}{|c|}{ Controls }} & \multicolumn{4}{|c|}{ VCM exposure } & \multirow{2}{*}{\multicolumn{2}{|c|}{ All }} \\
\hline Factor & Class & & & \multicolumn{2}{|c|}{ Low } & \multicolumn{2}{|c|}{ High } & & \\
\hline \multirow{3}{*}{$\begin{array}{l}\text { All } \\
\text { Age }\end{array}$} & & 29 & $7.2 \pm 0.1$ & 29 & $8.5 \pm 0.3$ & 32 & $8.9 \pm 0.3^{* *}$ & 90 & $8.2 \pm 0.2$ \\
\hline & $\geq 45$ years & 0 & & 18 & $8.8 \pm 0.4$ & 14 & $9.4 \pm 0.5$ & 32 & $9.0 \pm 0.3^{\# \#}$ \\
\hline & $<45$ years & 29 & $7.2 \pm 0.1$ & 11 & $8.0 \pm 0.3$ & 18 & $8.5 \pm 0.2$ & 58 & $7.7 \pm 0.1$ \\
\hline \multirow{2}{*}{$\begin{array}{l}\text { Duration of } \\
\text { employment } \\
\text { Smoking status }\end{array}$} & Yes & 14 & $7.6 \pm 0.2^{\# \#}$ & 16 & $9.1 \pm 0.4^{\# \#}$ & 20 & $8.9 \pm 0.3$ & 50 & $8.6 \pm 0.2^{\# \#}$ \\
\hline & No & 15 & $6.8 \pm 0.2$ & 13 & $7.7 \pm 0.2$ & 12 & $8.9 \pm 0.5$ & 40 & $7.7 \pm 0.2$ \\
\hline \multirow[t]{2}{*}{ Alcohol drinking } & Yes & 4 & $7.5 \pm 0.5$ & 7 & $8.8 \pm 0.7$ & 8 & $8.6 \pm 0.4$ & 19 & $8.5 \pm 0.3$ \\
\hline & No & 25 & $7.1 \pm 0.1$ & 22 & $8.4 \pm 0.3$ & 24 & $9.0 \pm 0.3$ & 71 & $8.1 \pm 0.2$ \\
\hline \multirow[t]{2}{*}{$X R C C 1$-exon 10} & $G \ln -G \ln$ & 1 & 6.3 & 3 & $11.4 \pm 1.7^{\# \#}$ & 3 & $8.7 \pm 1.0$ & 7 & $9.5 \pm 0.9$ \\
\hline & Arg-Arg/Arg-Gln & 28 & $7.2 \pm 0.1$ & 26 & $8.1 \pm 0.2$ & 29 & $8.9 \pm 0.3$ & 83 & $8.1 \pm 0.1$ \\
\hline GSTT1 & Non-null & 12 & $7.5 \pm 0.1$ & 16 & $8.6 \pm 0.4$ & 13 & $8.7 \pm 0.4$ & 41 & $8.2 \pm 0.2$ \\
\hline
\end{tabular}

** $P<0.01$, comparison between different VCM-exposure groups conducted with ANOVA

${ }^{\#} 0.01<P<0.05,{ }^{\#} P<0.01$, comparison between different age, smoking status, duration of employment, or genotype groups conducted with $t$-test

significantly higher frequency of SCE. Significantly higher SCE frequency was also found in those with greater duration of employment. The frequencies of SCE were found to be higher for individuals featuring the $X R C C 1$ Gln-Gln, the CYP2E1 c2c2, and ALDH2 1-2/2-2 genotypes. Interestingly, workers from the low VCMexposure group who featured XRCC1 Gln-Gln had significantly higher SCE than those who had XRCC1 Gln-Arg/Arg-Arg. Similarly, workers from the low VCMexposure group who featured $C Y P 2 E 1 c 2 c 2$ had significantly higher SCE than those who had CYP2E1c1c2/ $c 1 c 1$. The relationship is less prominent in high exposure groups. Those with $A L D H 2$ 1-2/2-2 genotypes revealed the higher SCE frequencies than those with $A L D H 2$ 1-1 genotypes in both high and low VCM-exposure groups, although the relationships were not significant. However, no significant association between SCE frequency and the GSTT1 genotype was found.
A multiple regression model (GLM) for SCE frequency as a function of age, smoking habit, alcohol consumption, VCM exposure, and genotypes of $X R C C 1, C Y P 2 E 1, A L D H 2, G S T T 1$ is shown in Table 4. In order to ensure the variation in different periods on SCE frequency, we also included a variable for the time periods (batch) of SCE assays in the GLM model. Duration of employment was excluded in this model because the variables of duration of employment and age had high colinearity $(r=0.88, P<0.01)$. The frequency of SCE was positively associated with an age greater than $45 \quad(P<0.01)$, and smoking status $(P=0.03)$. Relative to controls, a mean difference of 1.0 $\mathrm{SCE} /$ cell was noted for individuals experiencing a high VCM exposure $(P=0.03)$. Workers classified into the low VCM-exposure group experienced a mean difference of $0.6 \mathrm{SCE} /$ cell compared to controls $(P=0.16)$. Interestingly, greater frequencies of SCE were observed 
Table 4 Multiple regression model for frequencies of sister chromatid exchange per cell

\begin{tabular}{lccc}
\hline Variables & Regression coefficient & SE & $P$-value \\
\hline Intercept & 6.59 & 0.32 & $<0.01$ \\
Age: $\geq 45$ versus $<45$ (years) & 0.83 & 0.31 & $<0.01$ \\
Smoking status: yes versus none & 0.56 & 0.26 & 0.03 \\
Alcohol drinking: yes versus none & -0.21 & 0.33 & 0.52 \\
VCM exposure & 1.00 & 0.46 & 0.03 \\
$\quad$ High versus controls & 0.60 & 0.42 & 0.16 \\
Low versus controls & & & \\
Genotyping & 1.09 & 0.49 & 0.03 \\
XRCC1-exon $10:$ Gln-Gln versus Arg- Arg/Arg-Gln & 1.54 & 0.72 & 0.04 \\
CYP2E1: $c 2 c 2$ versus clcl/clc2 & 0.44 & 0.25 & 0.08 \\
ALDH2: $1-2 / 2-2$ versus $1-1$ & 0.12 & 0.25 & 0.63 \\
GSTT1: null versus non-null & 0.14 & 0.36 & 0.70 \\
Batch: before 1997 versus after 1997 & & &
\end{tabular}

amongst workers revealing the $X R C C l$ Gln-Gln genotype $(P=0.03)$, the $C Y P 2 E 1 c 2 c 2$ genotype $(P=0.04)$, or the ALDH2 $1-2 / 2-2 \quad(P=0.08)$ genotype. However, alcohol consumption $(P=0.52)$, the GSTT1 genotype $(P=0.63)$ and the experimental batch $(P=0.70)$ appeared not to influence the frequencies of SCE for individuals when examining the data using GLM analysis. In this model, the partial $R^{2}$-value for age was $4.7 \%$, for smoking was $5.1 \%$, for alcohol consumption was $0.3 \%$, for high VCM exposure was $11.9 \%$, for low VCM exposure was $12.5 \%$, for $X R C C 1$ was $3.7 \%$, for $C Y P 2 E 1$ was $3.7 \%$, and for $A L D H 2$ was $1.5 \%$.

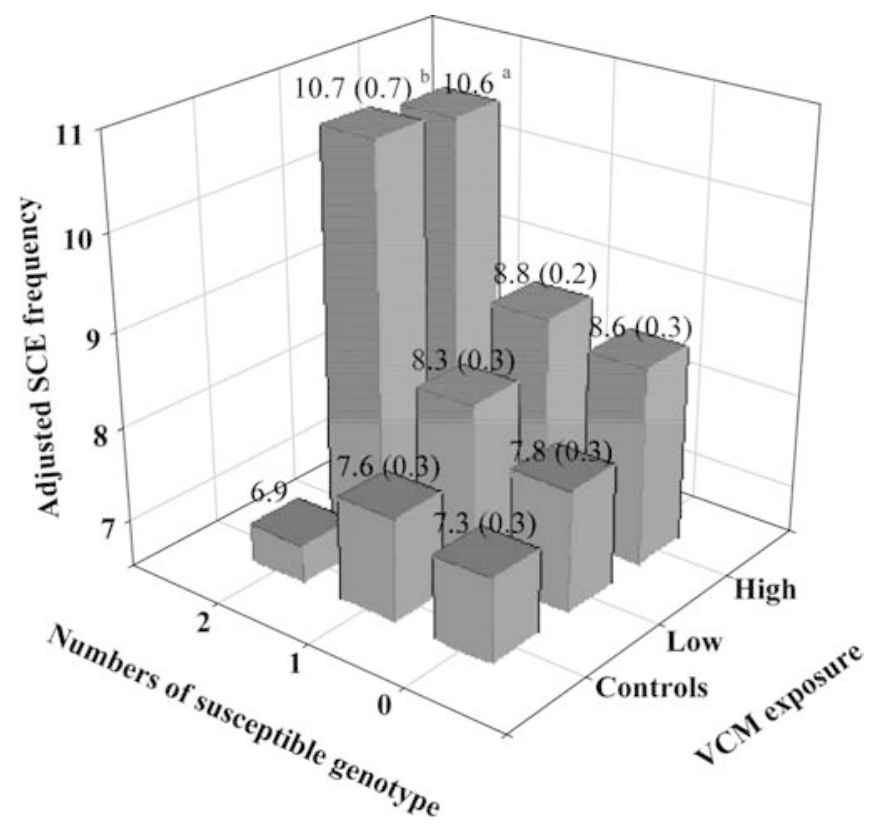

Fig. 1 Adjusted mean sister chromatid exchange (SCE) frequencies (standard errors in parentheses) according to the numbers of susceptible $C Y P 2 E 1, A L D H 2$ and $X R C C 1$ genotypes displayed and the vinyl chloride monomer (VCM) exposure adjusted for age

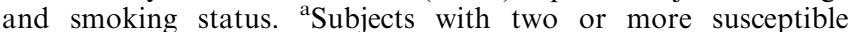
genotypes showed a higher SCE frequency than those with one such genotype $(P=0.12)$ or no susceptible genotypes $(P=0.09)$ in the high VCM-exposure group. 'Subjects with two or more susceptible genotypes also showed a higher SCE frequency than those with one such genotype $(P<0.01)$ or no susceptible genotypes $(P<0.01)$ in the low VCM-exposure group
Subsequently, a least-squares mean analysis was performed to assess the SCE frequency for study subjects expressing one or more susceptible $C Y P 2 E 1$, $A L D H 2$, and $X R C C 1$ genotypes, and applying VCM exposure adjusted for age and smoking habits (Fig. 1). In the low and high VCM-exposure groups, individuals possessing no susceptible genotypes revealed the lowest mean SCE frequencies compared to all other test groups, namely $7.8 \quad(n=14)$ and $8.6 \quad(n=11)$, respectively, whereas those subjects reflecting one susceptible genotype featured the slightly greater SCE frequencies of 8.3 $(n=12)$ and $8.8(n=20)$, respectively, whilst those with two or more susceptible genotypes demonstrated the greatest mean SCE frequencies of $10.7(n=3)$ and 10.6 $(n=1)$, respectively. Amongst the control group, those presenting with no susceptible genotypes revealed a mean SCE frequency of $7.3(n=13)$, and those featuring one susceptible genotype, or those individuals demonstrating two or more susceptible genotypes reflected mean SCE frequencies of $7.6(n=15)$ and $6.9(n=1)$, respectively. In addition, the trend in SCE frequency with the numbers of susceptible genotypes was shown to be statistically significant at $P<0.01$ (GLM) for the low VCM-exposure group, although no significant trend in SCE frequency with the numbers of susceptible genotypes was observed either for members of the high VCM-exposure group $(P=0.29)$ or for control subjects $(P=0.49)$.

\section{Discussion}

In this study, the metabolic $C Y P 2 E 1, A L D H 2$, and DNA-repair $X R C C 1$ genotypes, age and smoking habits, as well as high level of VCM exposure were significantly associated with SCE frequency.

The frequency of the $X R C C 1399 \mathrm{Gln}$ allele $(32.2 \%)$ in this study was consistent with the results of a previous study conducted upon Taiwanese subjects $(26.0 \%$; Lunn et al. 1999). The figure for the prevalence of the CYP2E1 $c 2$ allele noted in our study $(22.2 \%)$ appears to be quite similar to that reported in a previous study, again conducted upon people of Taiwanese descent $(20.3 \%$; Yu et al. 1995). The frequency of the presence of the 
$A L D H 2^{l}$ allele $(68.3 \%)$ was also comparable to that for the control groups of some literature-cited studies dealing with the investigation of alcoholism in the Taiwanese population (68-76\%; Thomasson et al. 1991; Chen et al. 1996b). The prevalence of the GSTT1 nulltype genotype in our study $(54.4 \%)$ appeared to be similar to that reported in a previous study, both for people of Chinese descent (64.4\%; Nelson et al. 1995) and of Taiwanese descent (51.4\%; Chen et al. 1996a). These findings, to some extent, corroborate the practice and results of our genotyping technique.

Importantly, an earlier animal study has revealed that VCM is metabolized by CYP2E1 to become CEO (el Ghissassi et al. 1998), which has the potential to spontaneously transform into CAA and then be metabolized by ALDH2 (Whysner et al. 1996). Both CEO and CAA are electrophiles ready to react with DNA bases to yield etheno adducts (Guengerich 1992). Certain DNA adducts have previously been found to be associated with SCE frequency (Ross et al. 1990; Wiencke et al. 1990). In our study, VCM-exposed workers reflecting the $C Y P 2 E 1 \quad c 2 c 2$ genotype demonstrated higher SCE frequencies than those without such a genotype. VCMexposed workers expressing the CYP2E1 $c 2 c 2$ genotype reflect a higher metabolic activity than those featuring the CYP2E1 clc1/c1c2 genotypes (Hayashi et al. 1991), and thus the former may be likely to experience elevated levels of genetic damage. We also observed an association between the presence of $A L D H 2$ 1-2/2-2 genotype and an increase in SCE frequency. From an earlier study, those individuals who revealed the presence of the $A L D H 2^{2}$ allele reflected a lower metabolic activity level than those possessing the $A L D H 2^{1}$ allele (Crabb et al. 1989), and hence the former may experience the accumulation of CAA in their bodies. Previous studies have also shown that GSTs may act as detoxification enzymes by reacting with the epoxide product of many different chemicals (Chen et al. 1996a; Nelson et al. 1995). However, there was no significant association between SCE frequency and GSTT1 genotype in the current study, although an association between GSTT1 and VCM-induced abnormal liver function in VCM-exposed workers has been reported (Huang et al. 1997). Thus, more studies are needed to determine the role of GSTT1 in VCM-related genotoxicity. Although GSTM1 has been reported to play a role in metabolizing epoxides of some compounds, our previous studies were unable to demonstrate any association between GSTM1 genotype and SCE frequency (Wong et al. 1998) or liver function (Huang et al. 1997) alteration in VCM-exposed workers. Thus, GSTM1 was not included in the analysis.

Several studies have already revealed the association between $X R C C 1$ and SCE frequency induced by alkylating agents (Zdzienicka et al. 1992) or by cigarette smoke (Duell et al. 2000; Lei et al. 2002). In this study, we also demonstrated that XRCC1 plays an important role in the genotoxicity elicited by VCM. Similar to metabolic genes, the presence of the XRCC1 Gln-Gln genotype was observed to be associated with higher SCE frequencies than when the XRCC1 Arg-Gln or $A r g-A r g$ genotype was present.

Our previous study also observed that an increased cumulative VCM exposure dose was associated with increased plasma p53 oncoprotein and anti-p53 antibody. In the same study, $C Y P 2 E 1$ and $X R C C 1$ genes were shown to modulate this p53 manifestation among VCM-exposed workers, while the effects of $A L D H 2$ and GSTT1 were not significant (Wong et al. 2002b). Both SCE and p53 represent genetic damage. The consistent results indicate that metabolic and DNA-repair genes may modulate VCM-induced genotoxicity, particularly the $C Y P 2 E 1$ and $X R C C 1$ genes.

Further analysis of $X R C C 1$ and other VCM-related metabolic genes, including $C Y P 2 E 1$ and $A L D H 2$, together revealed an increasing trend for these genotypes to reflect as an increase in SCE frequency for individuals from the low VCM-exposure group. This trend was not significant in the high VCM-exposure group probably due to a small number of subjects with susceptible genotypes. This might also be explained, from a metabolic point of view, by the fact that at high dose levels of VCM the relevant VCM-metabolizing enzyme becomes saturated for both rapid and slow metabolizers. This concept is supported by a previous study of rats, from which the metabolism of VCM at low concentrations was found to follow first-order kinetics and is perfusionlimited, reaching a plateau with increasing concentrations of VCM (Filser and Bolt 1979). Further, CYP2E1 is involved in the activation of VCM, $A L D H 2$ acting as a detoxifying enzyme for reactive metabolites of VCM, whilst $X R C C 1$ is involved in the subsequent DNA repair process. This also illustrates that VCM-exposed subjects who carry susceptible metabolic and/or DNA-repair genotypes are more likely to demonstrate an increased level of genotoxicity.

The limitation of this study is the small number of subjects with susceptible genotypes. We have tried to increase the number of susceptible genotypes in each cell by grouping XRCCl Gln-Gln and Gln-Arg, and CYP2E1 $c 2 c 2$ and $c 1 c 2$, respectively. However, SCE frequencies in subjects with at least one XRCC1 Gln or CYP2E1 c2 were not higher than those without susceptible gene alleles. It is not surprising for $C Y P 2 E 1$ because $C Y P 2 E 1$ $c 1 c 2$ has much lower enzyme activity than $C Y P 2 E 1 c 2 c 2$ (Hayashi et al. 1991). The relative enzyme activity for homozygous XRCC1 Gln-Gln and heterozygous XRCC1 Gln-Arg is not clear. Our recent study conducted in smokers also observed that the XRCC1 Gln-Gln genotype significantly modified the smoking-related SCE frequency, while XRCCl Gln-Arg did not (Lei et al. 2002). We also had similar findings in our previous study conducted in VCM-exposed workers. CYP2E1 c2c2 and $X R C C 1$ Gln-Gln modified the relationship between cumulative VCM doses and plasma p53 mutant protein (Wong et al. 2002b). Thus, results using either SCE or p53 as outcome indicators gave a similar finding on the role of XRCC1 Gln-Gln and CYP2E1c2c2 on VCM carcinogenesis. 
Our study has found that smoking and age are associated with an increased SCE frequency. Many studies have also shown that smoking can cause an increased SCE frequency (Hedner et al. 1982; Sarto et al. 1985; Cheng et al. 1999; Duell et al. 2000). Cigarette smoke contains a variety of known carcinogens, including polycyclic aromatic hydrocarbons (PAHs), aldehyde derivates, and vinyl chloride (Hoffmann et al. 1976). Thus, smoking is generally believed to be a strong inducer of SCE. In addition, it has previously been reported that there is a tendency amongst older individuals to show a higher SCE frequency than is the case for younger individuals (Hedner et al. 1982; Sarto et al. 1985). The observed increase in level of SCE amongst older subjects could be either due to the presence of cumulative damage caused by long-term exposure to unidentified carcinogens and/or mutagens, or from other factors related to cellular aging such as the relative integrity of the DNA repair process. In addition, an increased SCE frequency has reported in chronic alcoholics (Butler et al. 1981), and alcohol consumption has been reported to generate reactive oxygen species presumably through the effect of cytochrome P450 2E1 (Bailey and Cunningham 1998; Mali et al. 2001). However, the effect of alcohol on SCE frequency was not observed in our study. This was probably due to a small range in the level of alcohol consumption.

Age and smoking have been reported to account for about $30 \%$ of the variance in SCE frequency (Sarto et al. 1985; Hirsch et al. 1992). In this study, age and smoking accounted for about $10 \%$ of the variation, while VCM exposure contributed $20 \%$. Since VCM-exposed workers were older and tended to be smokers, the effects between age, smoking and VCM exposure cannot be separated. Interestingly, genotypes explained about $10 \%$ of the variation in SCE. A previous study also showed that genetic factors accounted for about $30 \%$ of the variation in SCE frequency (Hirsch et al. 1992). It will be intriguing to further investigate whether other genotypes contribute to the unexplained variation in SCE frequency.

The DMF-exposed workers and the VCM-exposed workers participating in this study were employed by the same plastics manufacturing company and they reflected a similar socioeconomic status. Thus, workers exposed to DMF are considered to be comparable to VCM-exposed workers, although DMF-exposed workers were younger than VCM-exposed workers in this study. In addition, we performed the cell cultures for SCE assay over two separate periods of time, and thus the potential for an influence on the results arising from a "batch effect" could not be totally excluded. However, the cultures were performed in the same laboratory and followed an identical protocol, and our model analysis indicated that the seasonal culture variation in SCE frequency was very small.

In summary, our results suggest that both metabolic and DNA-repair genes play a role in VCMinduced carcinogenesis. Further study to investigate the relationship of metabolic and DNA-repair genes with liver cancer is warranted.

Acknowledgements We thank Mr. Shing-Jen Hwang and Ms. Pei-Yi Chou for their technical assistance. This study was supported by NSC-89-2314-B-002-389 and NSC-90-2320-B-002-125, Taiwan. The experiments comply with the current regulations in Taiwan.

\section{References}

Antoine JL, Arany J, Leonard A, Henrotte J, Jenar-Dubuisson G, Decat G (1983) Lack of mutagenic activity of dimethylformamide. Toxicology 26:207-212

Bailey SM, Cunningham CC (1998) Acute and chronic ethanol increases reactive oxygen species generation and decreases viability in fresh, isolated rat hepatocytes. Hepatology 28:13181326

Butler MG, Sanger WG, Veonett GE (1981) Increased frequency of sister-chromatid exchanges in alcoholics. Mutat Res 85:71-76

Chen CJ, Yu MW, Liaw YF, Wang LW, Chiamprasert S, Matin F, Hirvonen A, Bell DA, Santella RM (1996a) Chronic hepatitis B carriers with null genotypes of glutathione $S$-transferase M1 and $\mathrm{T} 1$ polymorphisms who are exposed to aflatoxin are at increased risk of hepatocellular carcinoma. Am J Hum Genet 59:128-134

Chen WJ, Loh EW, Hsu YP, Chen CC, Yu JM, Cheng AT (1996b) Alcohol-metabolising genes and alcoholism among Taiwanese Han men: independent effect of $A D H 2, A D H 3$ and $A L D H 2 . \mathrm{Br}$ J Psychiatry 168:762-767

Cheng TJ, Hwang SJ, Kuo HW, Luo JC, Chang MJ (1999) Exposure to epichlorohydrin and dimethylformamide, glutathione $S$-transferases and sister chromatid exchange frequencies in peripheral lymphocytes. Arch Toxicol 73:282-287

Cheng TJ, Huang YF, Ma YC (2001) Urinary thiodiglycolic acid levels for VCM-exposed PVC workers. J Occup Environ Med 43:934-938

Crabb DW, Edenberg HJ, Bosron WF, Li TK (1989) Genotypes for aldehyde dehydrogenase deficiency and alcohol sensitivity. The inactive $A L D H 2^{2}$ allele is dominant. J Clin Invest 83:314316

Dosanjh MK, Chenna A, Kim E, Fraenkel-Conrat H, Samson L, Singer B (1994) All four known cyclic adducts formed in DNA by the vinyl chloride metabolite chloroacetaldehyde are released by a human DNA glycosylase. Proc Natl Acad Sci USA 91:1024-1028

Du CL, Chan CC, Wang JD (1996) Comparison of personal and area sampling strategies in assessing workers' exposure to vinyl chloride monomer. Bull Environ Contam Toxicol 56:534 542

Duell EJ, Wiencke JK, Cheng TJ, Varkonyi A, Zuo ZF, Ashok TD, Mark EJ, Wain JC, Christiani DC, Kelsey KT (2000) Polymorphisms in the DNA-repair genes $X R C C 1$ and ERCC2 and biomarkers of DNA damage in human blood mononuclear cells. Carcinogenesis 21:965-971

el Ghissassi F, Barbin A, Bartsch H (1998) Metabolic activation of vinyl chloride by rat liver microsomes: low-dose kinetics and involvement of cytochrome P450 2E1. Biochem Pharmacol 55:1445-1452

Filser JG, Bolt HM (1979) Pharmacokinetics of halogenated ethylenes in rats. Arch Toxicol 42:123-136

Fucic A, Barkovic D, Garaj-Vrhovac V, Kubelka D, Ivanic B, Dabo T, Mijic A (1996) A nine-year follow up study of a population occupationally exposed to vinyl chloride monomer. Mutat Res 361:49-53

Guengerich FP (1992) Roles of the vinyl chloride oxidation products 1-chlorooxirane and 2-chloroacetaldehyde in the in vitro formation of etheno adducts of nucleic acid bases. Chem Res Toxicol 5:2-5

Harada S, Zhang S (1993) New strategy for detection of ALDH2 mutant. Alcohol Alcohol Suppl 1A:11-13 
Hayashi S, Watanabe J, Kawajiri K (1991) Genetic polymorphisms in the $5^{\prime}$-flanking region change transcriptional regulation of the human cytochrome P450IIE1 gene. J Biochem 110:559-565

Hedner K, Hogstedt B, Kolnig AM, Mark-Vendel E, Strombeck B, Mitelman F (1982) Sister chromatid exchanges and structural chromosome aberrations in relation to age and sex. Hum Genet 62:305-309

Hirsch BA, Sentz KK, McGue M (1992) Genetic and environmental influences on baseline SCE. Environ Mol Mutagen 20:2-11

Hoffmann D, Patrianakos C, Brunnemann KD, Gori GB (1976) Chromatographic determination of vinyl chloride in tobacco smoke. Anal Chem 48:47-50

Huang CY, Huang KL, Cheng TJ, Wang JD, Hsieh LL (1997) The GST T1 and CYP2E1 genotypes are possible factors causing vinyl chloride induced abnormal liver function. Arch Toxicol 71:482-488

IPCS (International Programme on Chemical Safety) (1999) Environmental health criteria 215: vinyl chloride. World Health Organization/IPCS, Geneva, pp 313

Jones RD, Smith DM, Thomas PG (1988) A mortality study of vinyl chloride monomer workers employed in the United Kingdom in 1940-1974. Scand J Work Environ Health 14:153-160

Lei YC, Hwang SJ, Chang CC, Kuo HW, Luo JC, Chang MJW, Cheng TJ (2002) Effects on sister chromatid exchange frequency of polymorphisms in DNA repair gene XRCC1 in smokers. Mutat Res 519:93-101

Lunn RM, Langlois RG, Hsieh LL, Thompson CL, Bell DA (1999) $X R C C 1$ polymorphisms: effects on aflatoxin B1-DNA adducts and glycophorin A variant frequency. Cancer Res 59:2557-2561

Mari M, Wu D, Nieto N, Cederbaum AI (2001) CYP2E1-dependent toxicity and up-regulation of antioxidant genes. J Biomed Sci 8:52-58

Marintchev A, Robertson A, Dimitriadis EK, Prasad R, Wilson SH, Mullen GP (2000) Domain specific interaction in the XRCC1-DNA polymerase $\beta$ complex. Nucleic Acids Res 28:2049-2059

Nelson HH, Wiencke JK, Christiani DC, Cheng TJ, Zuo ZF, Schwartz BS, Lee BK, Spitz MR, Wang M, Xu X, Kelsey KT (1995) Ethnic differences in the prevalence of the homozygous deleted genotype of glutathione S-transferase theta. Carcinogenesis 16:1243-1245

Pemble S, Schroeder KR, Spencer SR, Meyer DJ, Hallier E, Bolt HM, Ketterer B, Taylor JB (1994) Human glutathione $S$ transferase $\theta(G S T T 1)$ : cDNA cloning and the characterization of a genetic polymorphism. Biochem J 300:271-276

Ross J, Nelson G, Kligerman A, Erexson G, Bryant M, Earley K, Gupta R, Nesnow S (1990) Formation and persistence of novel benzo $(a)$ pyrene adducts in rat lung, liver, and peripheral blood lymphocyte DNA. Cancer Res 50:5088-5094

Sarto F, Faccioli MC, Cominato I, Levis AG (1985) Aging and smoking increase the frequency of sister-chromatid exchanges (SCE) in man. Mutat Res 144:183-187
Shen MR, Jones IM, Mohrenweiser H (1998) Nonconservative amino acid substitution variants exist at polymorphic frequency in DNA repair genes in healthy humans. Cancer Res 58:604-608

Sinues B, Sanz A, Bernal ML, Tres A, Alcala A, Lanuza J, Ceballos C, Saenz MA (1991) Sister chromatid exchanges, proliferating rate index, and micronuclei in biomonitoring of internal exposure to vinyl chloride monomer in plastic industry workers. Toxicol Appl Pharmacol 108:37-45

Theriault G, Allard P (1981) Cancer mortality of a group of Canadian workers exposed to vinyl chloride monomer. J Occup Med 23:671-676

Thomasson HR, Edenberg HJ, Crabb DW, Mai XL, Jerome RE, Li TK, Wang SP, Lin YT, Lu RB, Yin SJ (1991) Alcohol and aldehyde dehydrogenase genotypes and alcoholism in Chinese men. Am J Hum Genet 48:677-681

Thompson LH, Brookman KW, Jones NJ, Allen SA, Carrano AV (1990) Molecular cloning of the human XRCC1 gene, which corrects defective DNA strand break repair and sister chromatid exchange. Mol Cell Biol 10:6160-6171

Whysner J, Conaway CC, Verna L, Williams GM (1996) Vinyl chloride mechanistic data and risk assessment: DNA reactivity and cross-species quantitative risk extrapolation. Pharmacol Ther 71:7-28

Wiencke JK, McDowell ML, Bodell WJ (1990) Molecular dosimetry of DNA adducts and sister chromatid exchanges in human lymphocytes treated with benzo $[a]$ pyrene. Carcinogenesis 11:1497-1502

Wong O, Whorton MD, Foliart DE, Ragland D (1991) An industry-wide epidemiologic study of vinyl chloride workers, 1942-1982. Am J Ind Med 20:317-334

Wong RH, Wang JD, Hsieh LL, Du CL, Cheng TJ (1998) Effects on sister chromatid exchange frequency of aldehyde dehydrogenase 2 genotype and smoking in vinyl chloride workers. Mutat Res 420:99-107

Wong RH, Chen PC, Du CL, Wang JD, Cheng TJ (2002a) An increased standardised mortality ratio for liver cancer among polyvinyl chloride workers in Taiwan. Occup Environ Med 59:405-409

Wong RH, Du CL, Wang JD, Chan CC, Luo JC, Cheng TJ (2002b) XRCC1 and CYP2E1 polymorphisms as susceptibility factors of plasma mutant p53 protein and anti-p53 antibody expression in vinyl chloride monomer-exposed polyvinyl chloride workers. Cancer Epidemiol Biomarkers Prev 11:475-482

Yu MW, Gladek-Yarborough A, Chiamprasert S, Santella RM, Liaw YF, Chen CJ (1995) Cytochrome P450 2E1 and glutathione $S$-transferase M1 polymorphisms and susceptibility to hepatocellular carcinoma. Gastroenterology 109:1266-1273

Zdzienicka MZ, van der Schans GP, Natarajan AT, Thompson LH, Neuteboom I, Simons JW (1992) A Chinese hamster ovary cell mutant (EM-C11) with sensitivity to simple alkylating agents and a very high level of sister chromatid exchanges. Mutagenesis 7:265-269 